\title{
Thyroid hormone ameliorates diabetic nephropathy in a mouse model of type II diabetes
}

\author{
Yi Lin and Zhongjie Sun \\ Department of Physiology, College of Medicine, University of Oklahoma Health Sciences Center, Oklahoma City, Oklahoma 73104, USA \\ (Correspondence should be addressed to Z Sun; Email: zhongjie-sun@ouhsc.edu)
}

\begin{abstract}
Conventional therapies for diabetic patients, such as strict glycemic control, do not completely stop the progression of diabetic nephropathy. Serum-free tri-iodothyronine $\left(\mathrm{T}_{3}\right)$ levels were lower in patients with type II diabetes. The purpose of this study was to test a hypothesis that treatment with $\mathrm{T}_{3}$ would improve diabetic nephropathy in $\mathrm{db} / \mathrm{db}$ mice, a model of type II diabetes. Male $\mathrm{db} / \mathrm{db}$ mice (16 weeks) were treated with $\mathrm{T}_{3}$ for 4 weeks. Urinary excretions of albumin and blood glucose levels were measured. Kidneys were collected for histological examination and molecular assays of transforming growth factor- $\beta 1$ (TGF- $\beta 1$ ) expression and phosphatidylinositol 3-kinase (PI3K). $\mathrm{T}_{3}$ attenuated albuminuria in $\mathrm{db} / \mathrm{db}$ mice, suggesting an improved kidney function. $\mathrm{T}_{3}$ significantly decreased accumulation of
\end{abstract}

collagenous components in cortical interstitium (interstitial fibrosis) and expansion of mesangial matrix in glomeruli (glomerulosclerosis) and prevented the loss of glomeruli in $\mathrm{db} / \mathrm{db}$ mice. Therefore, $\mathrm{T}_{3}$ improved the renal structural damage seen in diabetic mice. Notably, diabetic nephropathy was accompanied by a significant decrease in PI3K activity and an increase in TGF- $\beta 1$ expression in kidneys. $T_{3}$ restored renal $\mathrm{PI} 3 \mathrm{~K}$ activity, attenuated hyperglycemia, and decreased renal TGF- $\beta 1$ expression in $\mathrm{db} / \mathrm{db}$ mice. These effects of $\mathrm{T}_{3}$ were abolished by simultaneous treatment with PI3K inhibitor (LY294002). These data suggest that $T_{3}$ prevented progressive kidney damage and remodeling in $\mathrm{db} / \mathrm{db}$ mice by improving insulin signaling (e.g. PI3K activity).

Journal of Endocrinology (2011) 209, 185-191

\section{Introduction}

Diabetic nephropathy is now the most common cause of end-stage renal disease (ESRD), which significantly contributes to the high mortality in type II diabetic patients (Ruggenenti \& Remuzzi 1998). It is projected that $30-40 \%$ of patients with type I diabetes and $5-10 \%$ of patients with type II diabetes eventually develop ESRD (Ruggenenti \& Remuzzi 1998, Lin \& Sun 2010a). Conventional therapies such as strict glycemic control and antihypertensive treatment do not completely stop the progression of diabetic nephropathy in diabetic patients (Ruggenenti \& Remuzzi 1998).

The $\mathrm{db} / \mathrm{db}$ mouse is a useful animal model of type II diabetes with a point mutation in leptin receptor gene, which develops hyperglycemia, insulin resistance in peripheral tissues, and obesity by 8 weeks of age (Breyer et al. 2005). $\mathrm{The} \mathrm{db} / \mathrm{db}$ mice exhibit renal glomerular mesangial matrix expansion, increases in renal collagen and serum creatinine, albuminuria, and a decrease in glomerular filtration rate (GFR), which are comparable to advanced human diabetic nephropathy with renal insufficiency (Sharma et al. 2003).
Glomerular mesangial matrix expansion has been considered the essential characteristic of diabetic nephropathy in human (Sharma et al. 2003).

Hypothyroidism is accompanied by a decrease in GFR and renal blood flow (Iglesias \& Diez 2009). The low level of triiodothyronine $\left(\mathrm{T}_{3}\right)$ is associated with a survival disadvantage of chronic kidney disease (Iglesias \& Diez 2009). Type II diabetic patients with subclinical hypothyroidism are associated with an increased risk of diabetic nephropathy (Chen et al. 2007). In contrast, hyperthyroidism increases GFR and renal blood flow (Iglesias \& Diez 2009).

Clinical studies indicated that serum-free $\mathrm{T}_{3}$ level was about $47 \%$ lower in patients with type II diabetes compared with non-diabetic patients (Islam et al. 2008). There were no significant differences in serum levels of free thyroxine $\left(T_{4}\right)$ and TSH between the control and the study subjects (Islam et al. 2008). The serum level of $\mathrm{T}_{4}$ was lower in $\mathrm{db} / \mathrm{db}$ mice and the tissue level of $\mathrm{T}_{3}$ was lower in liver and brain due to impaired deiodination in these tissues of $\mathrm{db} / \mathrm{db}$ mice (Kaplan \& Young 1987). The purpose of this study was to test our hypothesis that chronic administration of $\mathrm{T}_{3}$ would attenuate diabetic nephropathy in $\mathrm{db} / \mathrm{db}$ mice. 


\section{Materials and Methods}

Animals

BKS.Cg- + Lepr $^{d b} /+$ Lepr $^{d b} /$ OlaHsd mice (db/db mice) and BKS.Cg- $m+/+$ Lepr $^{d b} /$ OlaHsd (lean mice) (all males, 12 weeks) were purchased from Harlan (Indianapolis, IN, USA). All mice were housed at room temperature $\left(25 \pm 1^{\circ} \mathrm{C}\right)$ and were provided with Purina laboratory chow (No. 5001) and tap water which was made available ad libitum. This study was approved by the Institutional Animal Care and Use Committee at the University of Oklahoma Health Sciences Center.

\section{Experimental protocol}

The kidneys used for this study were from the same groups of animals used in our previous publication on the effects of $\mathrm{T}_{3}$ on diabetes in $\mathrm{db} / \mathrm{db}$ mice (Lin \& Sun 2010b). Briefly, three groups of $\mathrm{db} / \mathrm{db}$ and three groups of lean mice were used (all 12 weeks, five mice/group). Following a 4-week control period, three groups of each strain (16 weeks) received i.p. injections of vehicles (35\% DMSO and PBS), $\mathrm{T}_{3}$ (7 ng/g b.w. in PBS, Sigma), and LY294002 (3 $\mu \mathrm{g} / \mathrm{g}$ dissolved in $35 \%$ DMSO, Sigma) followed by $\mathrm{T}_{3}$ respectively. The same doses of $T_{3}$ and LY294002 were given twice daily (0900 and $1700 \mathrm{~h})$ for 18 days $\left(14 \mathrm{ng} / \mathrm{g}\right.$ per day for $\mathrm{T}_{3}$ and $6 \mu \mathrm{g} / \mathrm{g}$ per day for LY294002). LY294002 was given $20 \mathrm{~min}$ before injection of $\mathrm{T}_{3}$. Animals were further treated with the increased dose of $\mathrm{T}_{3}(28 \mathrm{ng} / \mathrm{g}$ per day) and LY294002 $(9 \mu \mathrm{g} / \mathrm{g}$ per day) for another 10 days. A group treated with LY294002 alone was not included because the $\mathrm{db} / \mathrm{db}$ mice died within 2-3 days after treatments, probably due to severe hyperglycemia. At 4 weeks prior to the treatment and during week 4 of the treatment, 24-h urine samples were collected for measurements of urinary albumin.

At the end of week 4 of the treatments with $T_{3}$, animals were killed and blood was collected in EDTA for measuring blood glucose and plasma $T_{3}$. Blood glucose was measured using a Reli On Ultima glucose reader (Solartek Products, Inc., Alameda, CA, USA). Plasma $\mathrm{T}_{3}$ was measured using a $\mathrm{T}_{3}$ ELISA kit (Alpha Diagnostic International, San Antonio, TX, USA). Animals were then perfused transcardially using heparinized saline. Following perfusion, kidneys were isolated and weighed. The left kidney from each mouse was fixed with $4 \%$ paraformaldehyde in PBS for $24 \mathrm{~h}$. The kidneys were set in a plane perpendicular to the long axis and were embedded in paraffin for histological and immunohistochemical analysis.

\section{Measurements of albumin}

Urinary albumin excretion was measured with a mousespecific microalbuminuria ELISA kit (Albuwell M; Exocell, Philadelphia, PA, USA) according to the manufacturer's instruction.

\section{Morphological investigations}

A series of cross sections of the left kidney $(3-5 \mu \mathrm{m})$ were cut at the vascular poles. Tissue sections (four to five specimens per group) were stained with periodic acid Schiff (PAS), Masson's trichrome, or H\&E.

For sections stained with Masson's trichrome $(5 \mu \mathrm{m}$ thickness), images of cortex from three consecutive sections for each animal were collected at equal exposure conditions under Nikon Eclipse Ti microscopy (magnification $\times 100$ ). The fraction area for collagenous components in cortex was obtained with NIS-Elements BR 3.0 (Nikon, Melville, NY, USA). Images of sections for each animal were also collected at equal exposure conditions under the microscopy at the magnification of 400 .

For sections stained with PAS $(3 \mu \mathrm{m})$, images of 20 glomeruli for each animal were collected at equal exposure conditions and at the magnification of 400 under a microscopy (Nikon Eclipse Ti). Mesangial matrix area was defined by
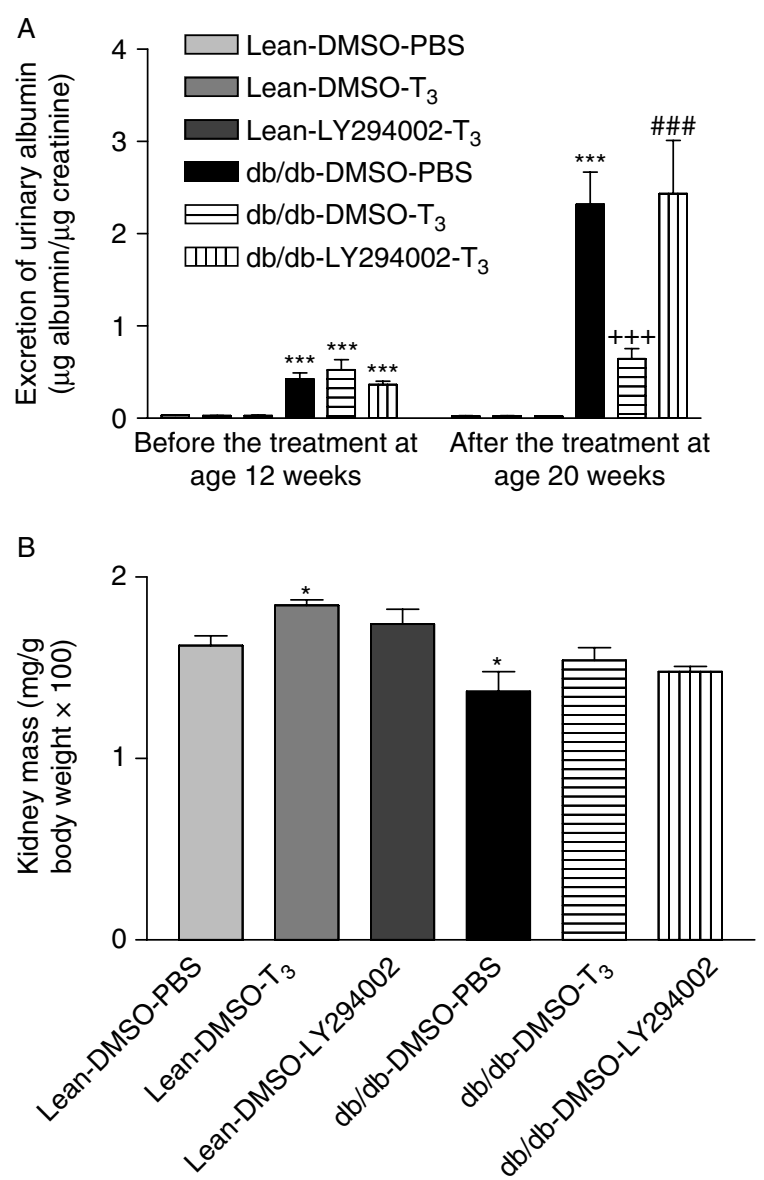

Figure 1 Treatments with $T_{3}$ decreased albuminuria in $\mathrm{db} / \mathrm{db}$ mice. $T_{3}$ decreased urinary albumin excretion in $\mathrm{db} / \mathrm{db}$ mice (A). $T_{3}$ increased kidney mass in lean and $\mathrm{db} / \mathrm{db}$ mice (B). Data $=$ mean \pm S.E.M. $n=5 . * P<0 \cdot 05, * * * P<0 \cdot 001$ versus lean-DMSO-PBS group; ${ }^{+++} P<0 \cdot 001$ versus $\mathrm{db} / \mathrm{db}-\mathrm{DMSO}-\mathrm{PBS} ;{ }^{\# \#} P<0 \cdot 001$ versus $\mathrm{db} / \mathrm{db}-\mathrm{DMSO}-\mathrm{T}_{3}$. 
PAS-positive and nuclei-free area in the mesangium. The glomerular area was defined by tracing along the borders of the capillary loop. Relative mesangial area (defined as fraction area of mesangial matrix area over glomerular area) was obtained using Image J (NIH freeware, Bethesda, MD, USA).

For sections stained with $\mathrm{H} \& \mathrm{E}(5 \mu \mathrm{m})$, the number of glomeruli was quantified using Nikon Eclipse Ti microscopy at a magnification of 100 . Briefly, the kidneys were sectioned in a plane perpendicular to the long axis, beginning at the vascular poles. The kidneys were cut at $250 \mu \mathrm{m}$ intervals. The number of glomeruli was quantified in three randomly chosen fields in each section and averaged based on five consecutive sections for each animal. The area $\left(\mathrm{mm}^{2}\right)$ of each field was measured. Images of cortex for each animal were also collected at equal exposure conditions at a magnification of 400 .

\section{Phosphatidylinositol 3-kinase activity}

Lysates of mouse kidney were immunoprecipitated with antibody against phosphatidylinositol 3-kinase (PI3K; Millipore, Temecula, CA, USA). PI3K activity in the immunocomplexes was determined using a PI3K ELISA kit (Echelon Biosciences, Salt Lake City, UT, USA).

\section{Western blotting}

Lysates of mouse kidney under reduced conditions were directly subjected to SDS-PAGE followed by western blotting with an antibody against transforming growth factor- $\beta 1$ (TGF- $\beta 1$; Santa Cruz Biotechnology, Santa Cruz, CA, USA, TGF- $\beta 1$ and its precursor) and then with an antibody against $\beta$-actin (Santa Cruz) after stripping the blot.

\section{Statistical analysis}

Data were analyzed using a two-way ANOVA (strain and treatments). The Newman-Keuls procedure was used to assess differences between means. Data were expressed as mean \pm s.E.M. A value with $P<0.05$ was considered significant.

\section{Results}

\section{$T_{3}$ decreased urinary albumin excretion in diabetic mice}

At the age of 12 weeks, the $\mathrm{db} / \mathrm{db}$ mice had a significantly higher level of urinary albumin than that of the lean mice (Fig. 1A). No significant difference of urinary albumin excretion was found between any two groups of $d b / d b$ mice or lean mice at the age of 12 weeks (Fig. 1A). Albuminuria of the $\mathrm{db} / \mathrm{db}$ mice at the age of 20 weeks was significantly increased compared with that at the age of 12 weeks (Fig. 1A). Treatment with $\mathrm{T}_{3}$ significantly decreased albuminuria in $\mathrm{db} /$ $\mathrm{db}$ mice (Fig. 1A). Treatment with PI3K inhibitor (LY294002) abolished the beneficial effect of $\mathrm{T}_{3}$ on albuminuria in $\mathrm{db} / \mathrm{db}$ mice (Fig. 1A), suggesting that this effect may be mediated by PI3K.

There was a significant decrease in kidney mass in the $\mathrm{db} / \mathrm{db}-\mathrm{DMSO}-\mathrm{PBS}$ group (control) versus the lean-DMSO-PBS group at the age of 20 weeks (Fig. 1B). Treatment with $\mathrm{T}_{3}$ significantly increased the kidney mass in lean mice (Fig. 1B). Body weight was significantly greater in the $\mathrm{db} / \mathrm{db}$-DMSO-PBS group than in the lean groups (Lin \& Sun 2010b). Treatment with $\mathrm{T}_{3}$ did not affect body weights in either lean or $\mathrm{db} / \mathrm{db}$ mice (Lin \& Sun 2010b).

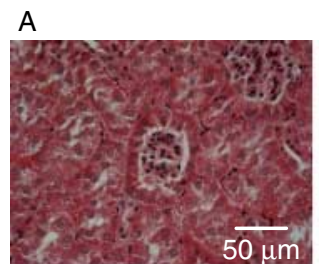

Lean-DMSO-PBS

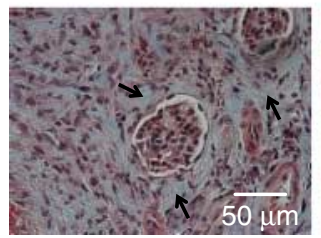

$\mathrm{db} / \mathrm{db}$-DMSO-PBS

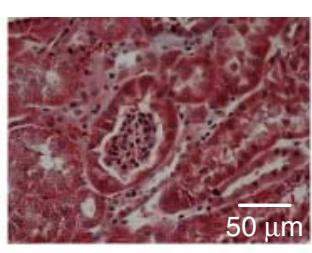

Lean-DMSO-T

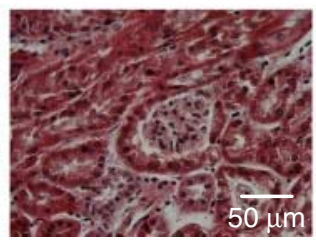

$\mathrm{db} / \mathrm{db}-\mathrm{DMSO}_{3}$

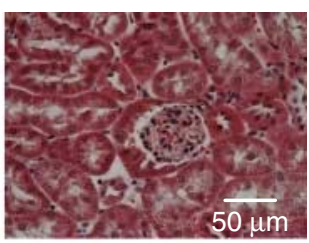

Lean-LY294002-T

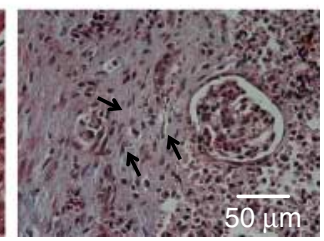

$\mathrm{db} / \mathrm{db}-\mathrm{LY}_{2} 29002-\mathrm{T}_{3}$
B

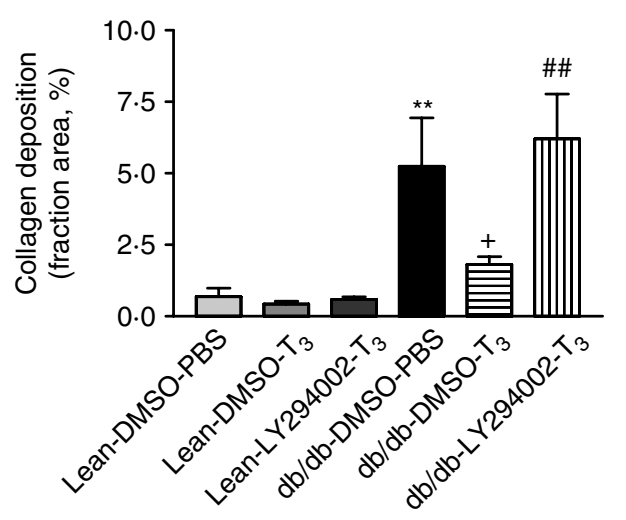

Figure 2 Treatment with $\mathrm{T}_{3}$ attenuated collagen deposition in renal cortex of $\mathrm{db} / \mathrm{db}$ mice. Representative photomicrographs of Masson's trichrome-stained kidney sections with original magnification $\times 400$ (A). Arrows indicate trichrome-positive collagenous components in cortical interstitium (blue). Kidney sections were cut at their vascular poles. Quantitative analysis of collagenous components in renal cortex (B). Images of cortex from three consecutive sections for each animal, collected at equal exposure conditions under Nikon Eclipse Ti microscopy $(\times 100)$, were used in the analysis. Data $=$ mean \pm s.E.M. $n=4-5 .{ }^{* *} P<0 \cdot 01$ versus the lean-DMSO-PBS; ${ }^{+} P<0 \cdot 05$ versus the $\mathrm{db} / \mathrm{db}-\mathrm{DMSO}-\mathrm{PBS}$ group; ${ }^{\#} P<0 \cdot 01$ versus the $\mathrm{db} / \mathrm{db}-\mathrm{DMSO}-\mathrm{T}_{3}$ group. 
$T_{3}$ attenuated collagen accumulation in kidney cortex in diabetic mice

The Masson trichrome staining showed that the 20-week-old $\mathrm{db} / \mathrm{db}$ mice had significantly higher levels of collagenous components in cortical interstitium compared with those of the lean mice (Fig. 2A and B). Treatments with $\mathrm{T}_{3}$ significantly decreased collagenous components in $\mathrm{db} / \mathrm{db}$ mice (Fig. 2A and B). PI3K inhibitor abolished the beneficial effect of $T_{3}$ (Fig. $2 A$ and B). These data indicated that $T_{3}$ prevented interstitial fibrosis in $\mathrm{db} / \mathrm{db}$ mice and that PI3K was important in mediating this beneficial effect in $\mathrm{db} / \mathrm{db}$ mice.

\section{$T_{3}$ decreased glomerular mesangial matrix expansion in diabetic mice}

The $\mathrm{db} / \mathrm{db}$ mice showed significant glomerular mesangial matrix expansion compared with the lean mice (Fig. 3A and $\mathrm{B})$, indicating glomerular remodeling. Treatments with $\mathrm{T}_{3}$ abolished glomerulosclerosis in $\mathrm{db} / \mathrm{db}$ mice (Fig. 3A and B). PI3K inhibitor partially blocked the effect of $\mathrm{T}_{3}$ on the mesangial matrix expansion.

\section{$T_{3}$ attenuated kidney damage in diabetic mice}

$\mathrm{The} \mathrm{db} / \mathrm{db}$ mice showed renal tubule atrophy, some lost typical structures of cortical tubules (Fig. 4A), suggesting renal remodeling in diabetic mice. $\mathrm{T}_{3}$ restored tubular structures (Fig. 4A). The number of glomeruli was significantly decreased in the $\mathrm{db} / \mathrm{db}$-DMSO-PBS group compared with the lean-DMSO-PBS groups (Fig. 4B), suggesting a loss of glomeruli at the age of 20 weeks. The glomeruli were replaced by massive cellular infiltrates in the diabetic mice. $T_{3}$ prevented the loss of glomeruli in the $\mathrm{db} / \mathrm{db}$ mice (Fig. 4B). These beneficial effects of $\mathrm{T}_{3}$ may be mediated by PI3K because they could be abolished by the PI3K inhibitor (Fig. 4B).

\section{$T_{3}$ increased PI $3 \mathrm{~K}$ activities in kidneys and attenuated} hyperglycemia in diabetic mice

The $\mathrm{PI} 3 \mathrm{~K}$ activity ( $\mathrm{PIP}_{3}$ products) was significantly lower in kidneys of the $\mathrm{db} / \mathrm{db}$-DMSO-PBS mice than that in the lean mice (Fig. 5). $\mathrm{T}_{3}$ significantly increased the PI3K activity in kidneys of both $\mathrm{db} / \mathrm{db}$ and lean mice (Fig. 5). The PI3K inhibitor abolished the stimulating effects of $\mathrm{T}_{3}$ on PI3K activities.

The blood glucose level was significantly higher in the $\mathrm{db} / \mathrm{db}-\mathrm{DMSO}-\mathrm{PBS}$ mice than in the lean mice (Lin \& Sun $2010 b) . T_{3}(14 \mathrm{ng} / \mathrm{g}$ per day) significantly attenuated the blood glucose level in the $\mathrm{db} / \mathrm{db}$ mice but not in the lean mice. An increase in the dose of $\mathrm{T}_{3}(28 \mathrm{ng} / \mathrm{g}$ per day) further attenuated hyperglycemia (Lin \& Sun 2010b). The PI3K inhibitor abolished the anti-hyperglycemic effects of $\mathrm{T}_{3}$ (Lin \& Sun 2010b).

The basal level of plasma $\mathrm{T}_{3}$ in $\mathrm{db} / \mathrm{db}$ mice $(61.7$ $\pm 5 \cdot 2 \mathrm{ng} / \mathrm{dl})$ was significantly lower than that of the lean mice $(86 \cdot 5 \pm 7 \cdot 2 \mathrm{ng} / \mathrm{dl})$. Daily administration of $\mathrm{T}_{3}(28 \mathrm{ng} / \mathrm{g}$ per day) for 7 days increased the plasma levels of $\mathrm{T}_{3}$ by $2 \cdot 7$ folds in $\mathrm{db} / \mathrm{db}$ mice (Lin \& Sun 2010b). As we reported recently (Lin \& Sun 2010b), the basal level of plasma insulin was not significantly different between the lean and the $\mathrm{db} / \mathrm{db}$ mice, although the latter had severe hyperglycemia. Treatment with $\mathrm{T}_{3}$ significantly increased the plasma level of insulin (Lin \& Sun 2010b).
A
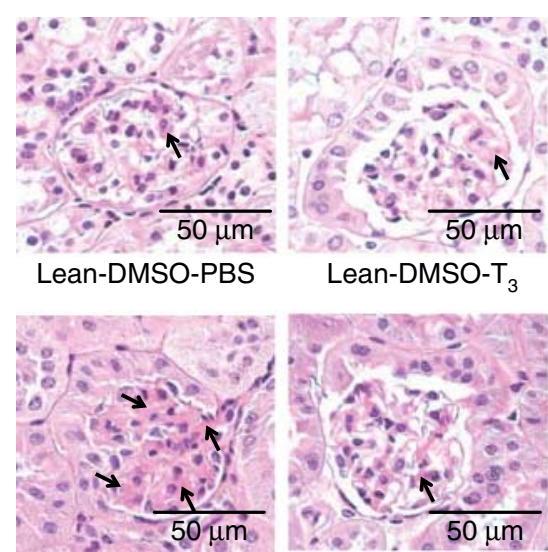

$\mathrm{db} / \mathrm{db}$-DMSO-PBS

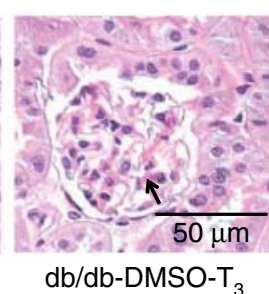

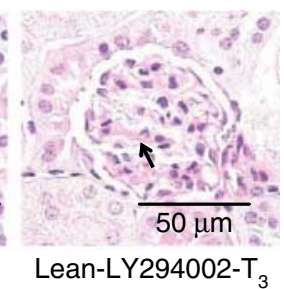

B

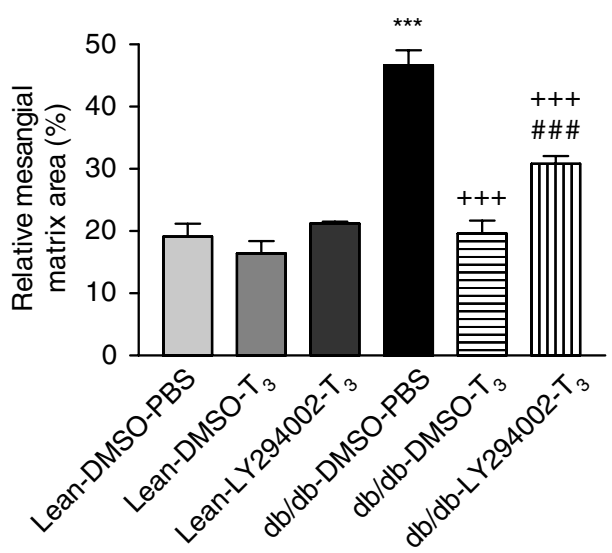

Figure 3 Treatment with $\mathrm{T}_{3}$ prevented mesangial matrix expansion in db/db mice. Representative photomicrographs of PAS-stained kidney sections with original magnification of $\times 400$ (A). Arrows indicate PAS-positive mesangial material (pink). Quantitative measurements of mesangial matrix expansion (B). Relative mesangial matrix area is expressed as PAS-positive mesangial matrix per total glomerular tuft crosssectional area. Kidney sections were cut at their vascular poles. An average value was obtained from analyses of 20 glomeruli per mouse. Data $=$ mean \pm s.E.M. $n=4-5 .{ }^{* * *} P<0 \cdot 001$ versus the lean-DMSO-PBS group; ${ }^{+++} P<0 \cdot 001$ versus the db/db-DMSO-PBS group;

$\# \# P<0 \cdot 001$ versus the $\mathrm{db} / \mathrm{db}$-DMSO-T 3 group. 


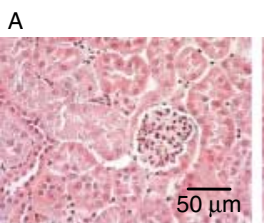

Lean-DMSO-PBS

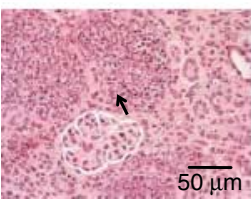

$\mathrm{db} / \mathrm{db}-\mathrm{DMSO}-\mathrm{PBS}$

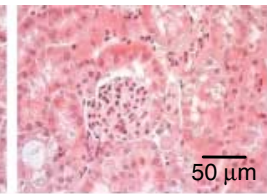

Lean-DMSO-T

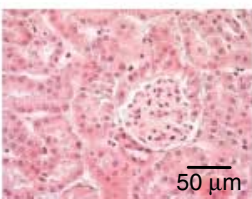

$\mathrm{db} / \mathrm{db}-\mathrm{DMSO}-\mathrm{T}_{3}$

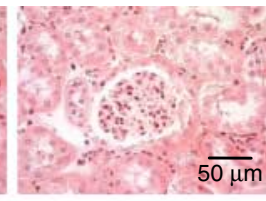

Lean-LY294002-T

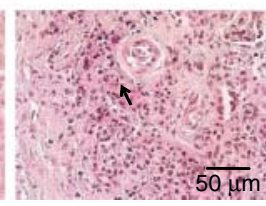

$\mathrm{db} / \mathrm{db}-\mathrm{LY}_{2} 94002-\mathrm{T}_{3}$
B

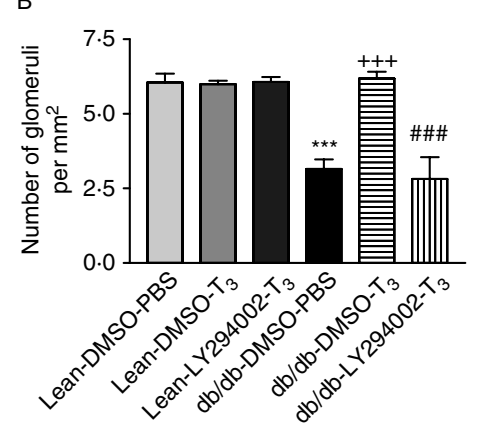

Figure 4 Treatments with $T_{3}$ prevented cellular infiltration in cortical tubules and glomeruli and restored the number of glomeruli in kidney in $\mathrm{db} / \mathrm{db}$ mice. Representative photomicrographs of H\&E-stained kidney cortical sections showing typical structures of cortical glomeruli and tubules with original magnification of $\times 400$ (A). Arrows indicate cellular infiltration. The average number of glomeruli was obtained from three groups of identical $5 \mu \mathrm{m}$ cross sections separated by the $250 \mu \mathrm{m}$ intervals (B). Data $=$ mean \pm S.E.M. $n=4-5 .{ }^{* * *} P<0 \cdot 001$ versus the lean-DMSOPBS group; ${ }^{++}+P<0 \cdot 001$ versus the $\mathrm{db} / \mathrm{db}-\mathrm{DMSO}-\mathrm{PBS}$ group; $\# \# P<0 \cdot 001$ versus the $\mathrm{db} / \mathrm{db}-\mathrm{DMSO}-\mathrm{T}_{3}$ group.

\section{$T_{3}$ decreased TGF- $\beta 1$ expression in kidneys of diabetic mice}

The basal level of TGF- $\beta 1$ (precursor) expression was barely detectable in lean mice (Fig. 6). TGF- $\beta 1$ expression was significantly increased in the $\mathrm{db} / \mathrm{db}-\mathrm{DMSO}-\mathrm{PBS}$ mice compared with the lean mice (Fig. 6). $\mathrm{T}_{3}$ significantly decreased TGF- $\beta 1$ expression (Fig. 6). Notably, inhibition of PI3K not only abolished the effect of $\mathrm{T}_{3}$ on TGF- $\beta 1$ expression but also significantly increased the TGF- $\beta 1$ level above that of the $\mathrm{db} / \mathrm{db}-\mathrm{DMSO}-\mathrm{PBS}$ group.

\section{Discussion}

Renal fibrosis, including tubulointerstitial and glomerular fibrosis, is an important feature of diabetic nephropathy (Brosius 2008). Interstitial fibrosis seems to contribute to the deterioration of renal function, especially during the late stage of diabetic nephropathy (Brosius 2008). Diabetic glomerular fibrosis is mainly due to accumulation of extracellular matrix proteins such as collagen and fibronectin in the mesangial interstitial space, which results in progressive diabetic nephropathy by reducing the surface area of glomerular capillaries for filtration (Steffes et al. 1989, Brosius 2008). This study showed that there was renal structural remodeling as evidenced by a loss of typical structures of renal tubules and glomeruli in $\mathrm{db} / \mathrm{db}$ mice (Figs 2 and 4). The loss of glomeruli in $\mathrm{db} / \mathrm{db}$ mice is surprising as it has not been observed in human and other experimental models of type II diabetes. The loss of glomeruli and cellular infiltration in the late stage of diabetes may be due to hyperglycemia-related vascular damages (Lehmann \& Schleicher 2000, Koya et al. 2003). It is known that long-term hyperglycemia causes vascular oxidative stress resulting in vascular damage and cellular infiltration (Suzuki \& Miyata 1999, Lehmann \& Schleicher 2000, Koya et al. 2003), which may be eventually replaced by fibrosis (Lehmann \& Schleicher 2000). Interestingly, treatments with $\mathrm{T}_{3}$ prevented accumulation of collagenous components in cortical interstitium and glomerular mesangial matrix expansion in diabetic mice (Figs 2 and 3 ).

TGF- $\beta$ has been shown to be linked to renal fibrosis in diabetic nephropathy in animals and humans (Lehmann \& Schleicher 2000, Zhu et al. 2007, Chiarelli et al. 2009). Suppression of TGF- $\beta 1$ inhibited hyperglycemia-induced collagen synthesis and prevented glomerular fibrosis and renal insufficiency in $\mathrm{db} / \mathrm{db}$ mice (Lehmann \& Schleicher 2000, Ziyadeh et al. 2000). This study revealed that $T_{3}$ significantly attenuated the increase in TGF- $\beta 1$ expression in kidneys of $\mathrm{db} / \mathrm{db}$ mice (Fig. 6). This effect may be mediated by an increase in PI3K activity because inhibition of PI3K abolished

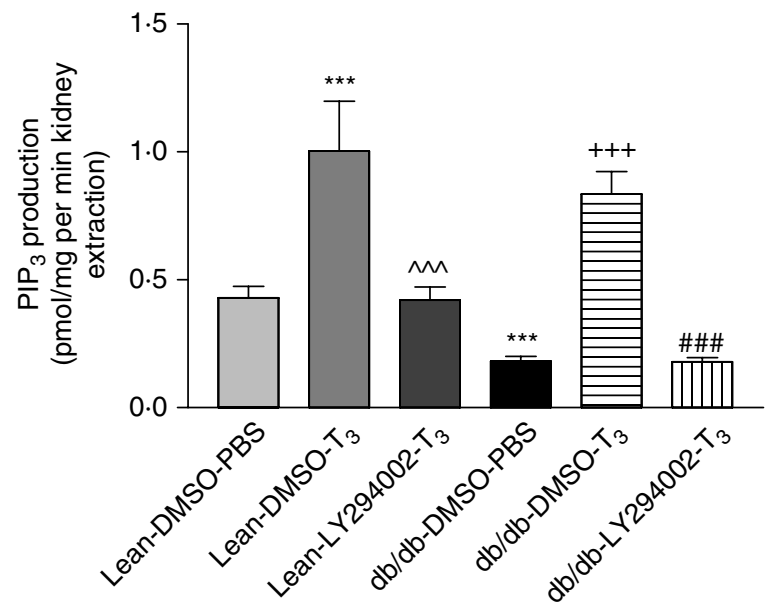

Figure 5 Treatment with $\mathrm{T}_{3}$ enhanced the activities of $\mathrm{PI} 3 \mathrm{~K}$ in kidneys of $\mathrm{db} / \mathrm{db}$ mice. PI3K activity in kidneys was measured with a kit after tissue lysates were immunoprecipitated with antibody against PI3K. Data were normalized to the amount of protein used in the immunoprecipitation and the time for enzyme reaction. Data $=$ mean \pm S.E.M. $n=5 .{ }^{* * *} P<0 \cdot 001$ versus the lean-DMSOPBS group; ${ }^{\wedge \wedge} P<0 \cdot 001$ versus the lean-DMSO- $T_{3}$ group; $+++P<0.001$ versus the $\mathrm{db} / \mathrm{db}$-DMSO-PBS group; ${ }^{\# \#} P<0.001$ versus the $\mathrm{db} / \mathrm{db}-\mathrm{DMSO}-\mathrm{T}_{3}$ group. 

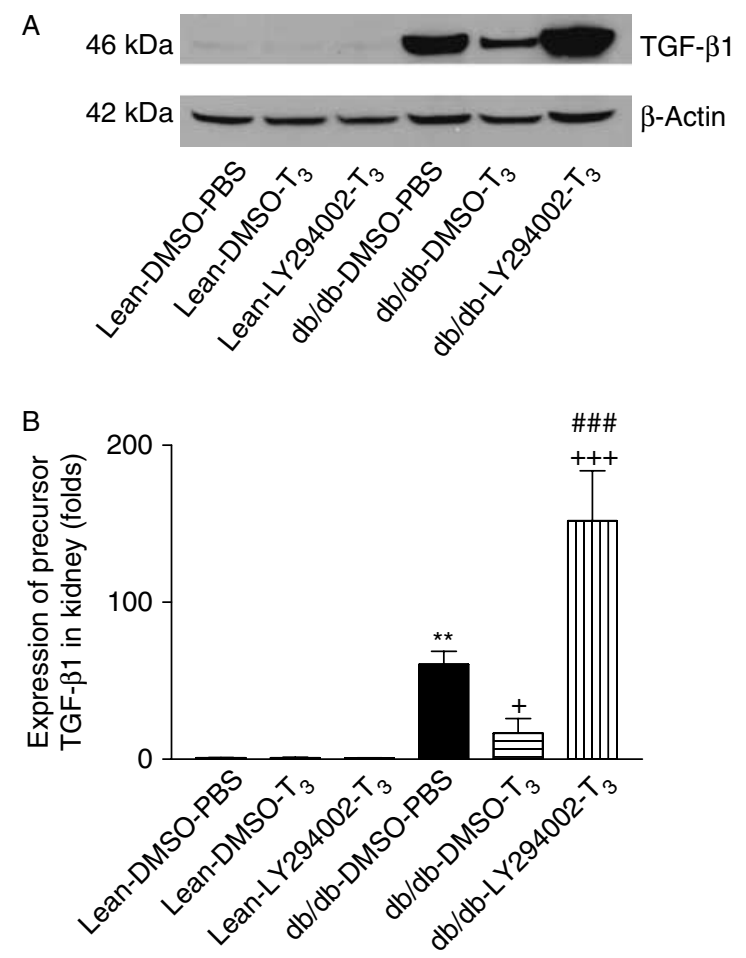

Figure 6 Treatment with $T_{3}$ deceased TGF- $\beta 1$ expression in kidneys of $\mathrm{db} / \mathrm{db}$ mice. Representative western blotting of TGF- $\beta 1$ and $\beta$-actin (A). Quantification of TGF- $\beta 1$ expression (B). TGF- $\beta 1$ was normalized with $\beta$-actin, which was then calculated as fold changes of the control (lean-DMSO-PBS) group. Data $=$ mean \pm s.E.M. $n=5$. ${ }^{* *} P<0.01$ versus the lean-DMSO-PBS group; ${ }^{+} P<0 \cdot 05$, $+++P<0.001$ versus the $\mathrm{db} / \mathrm{db}$-DMSO-PBS; ${ }^{\# \#} P<0 \cdot 001$ versus the $\mathrm{db} / \mathrm{db}-\mathrm{DMSO}-\mathrm{T}_{3}$ group.

the attenuating effect of $T_{3}$ on the up-regulation of TGF- $\beta 1$ in diabetic kidneys (Fig. 6). This finding further suggested that PI3K may be involved in the up-regulation of TGF- $\beta 1$ in diabetic nephropathy. Further studies are required to determine whether PI3K regulates TGF- $\beta 1$ via its direct action on TGF- $\beta 1$ or through its effect on glycemia in diabetic kidneys. Therefore, the beneficial effects of $\mathrm{T}_{3}$ on diabetic nephropathy may be mediated, at least in part, by its attenuating effect on TGF- $\beta 1$ expression. These findings also support a notion that thyroid hormone is an important regulator of renal structure in diabetic mice.

Although renal hypertrophy is found in the early stage of diabetes (Sharma et al. 2003), this study showed that kidney mass did not remain increased in diabetic mice at the age of 20 weeks (Fig. 1B). This finding is consistent with a report that renal hypertrophy disappears in $\mathrm{db} / \mathrm{db}$ mice at the age of 21 and 25 weeks (Koya et al. 2000). The decrease in kidney mass is probably due to the loss of glomeruli and tubules and structural remodeling at a late stage of diabetes.

The $\mathrm{db} / \mathrm{db}$ mice showed progressive renal functional damage as evidenced by a significant increase in urinary excretion of albumin (Fig. 1A), which is consistent with the published data (Ziyadeh et al. 2000, Cohen et al. 2001). Notably, treatments with $\mathrm{T}_{3}$ markedly ameliorated renal functional damage. Plasma $\mathrm{T}_{3}$ levels were significantly decreased in $\mathrm{db} / \mathrm{db}$ mice (Lin \& Sun 2010b). It was reported that female $\mathrm{db} / \mathrm{db}$ mice aged 7 weeks have lower $\mathrm{T}_{4}$ levels in serum and lower $\mathrm{T}_{3}$ levels in the liver and brain (Kaplan \& Young 1987). An epidemiological study indicated that type II diabetic patients with subclinical hypothyroidism are associated with an increased risk of diabetic nephropathy (Chen et al. 2007). The GFR in hypothyroid patients is approximately one-third lower than that of the euthyroid individuals (Singer 2001). Suher et al. (2005) showed that subjects with hypothyroidism are associated with increased urinary albumin excretion rate and decreased creatinine clearance. In corroboration with our findings, $\mathrm{T}_{3}$ was reported to have beneficial effects on renal function in a diabetic patient with end-stage renal failure and severe hypothyroidism (van Welsem \& Lobatto 2007). Renal function was improved by $\mathrm{T}_{3}$ in 32 patients with hypothyroidism (den Hollander et al. 2005). Therefore, treatments with thyroid hormone may be an effective therapeutic approach for delaying progressive renal damage or even renal failure in diabetic patients with hypothyroidism or subclinical hypothyroidism.

Given that hyperglycemia may be involved in the development of diabetic nephropathy (Brosius 2008) and that $\mathrm{T}_{3}$ decreased blood glucose levels in $\mathrm{db} / \mathrm{db}$ mice (Fig. $5 \mathrm{~A}$ and $\mathrm{B}$ ), the anti-hyperglycemic effect of $\mathrm{T}_{3}$ may contribute to its protective effects on diabetic nephropathy. On the other hand, strict glycemic control does not completely stop the progression of diabetic nephropathy in diabetic patients (Ruggenenti \& Remuzzi 1998). It is noted that $\mathrm{T}_{3}$ restored the decreased activity of PI3K in diabetic kidneys (Fig. 5C). The present data suggest that $T_{3}$ ameliorated diabetic nephropathy in $\mathrm{db} / \mathrm{db}$ mice, probably by increasing PI3K activity because inhibition of PI3K activity abolished the beneficial effect of $T_{3}$. Therefore, the beneficial effects of $T_{3}$ on diabetic nephropathy may be mediated by the increased insulin synthesis and release, enhanced insulin signaling, and improved insulin resistance by $\mathrm{T}_{3}$ (Lin \& Sun 2010b). The limitation of this study is that it cannot determine the relative importance of the increased renal PI3K activity and the attenuated hyperglycemia in the beneficial effect of $T_{3}$ on diabetic nephropathy. A further study is needed to address this important question by controlling glucose levels in all groups.

The PI3K/AKT signaling was activated in renal cortex of $\mathrm{db} / \mathrm{db}$ mice in the early phase of diabetes (at ages of 6-8 weeks) likely due to an increase in insulin receptor activities (Feliers et al. 2001). Activation of the PI3K/AKT signaling has been considered an important factor for diabetic renal hypertrophy, which contributes to diabetic nephropathy (Price 2007). On the other hand, the PI3K/AKT signaling was found to be lower in glomeruli of 12 -week-old $\mathrm{db} / \mathrm{db}$ mice, which has been linked to the death of podocytes of $\mathrm{db} / \mathrm{db}$ mice (Tejada et al. 2008). Most recent data indicated that the down-regulation of PI3K/AKT signaling contributes 
to renal tubular apoptosis in kidneys of streptozotocininduced diabetic mice and apoptosis in renal proximal tubular cells (Rane et al. 2010). Apoptosis has been considered as an initiator of diabetic nephropathy (Kumar et al. 2004). Therefore, the PI3K/AKT signaling may play different roles at different stages of diabetic nephropathy.

\section{Declaration of interest}

The authors declare that there is no conflict of interest that could be perceived as prejudicing the impartiality of the research reported.

\section{Funding}

This work was supported by NIH R01 HL077490.

\section{Author contribution statement}

$\mathrm{Z} \mathrm{S}$ conceived and designed the experiment and wrote the paper. $\mathrm{Y} L$ designed and performed the experiments, analyzed the data, and wrote the paper.

\section{References}

Breyer MD, Bottinger E, Brosius FC III, Coffman TM, Harris RC, Heilig CW \& Sharma K 2005 Mouse models of diabetic nephropathy. Journal of the American Society of Nephrology 16 27-45. (doi:10.1681/ASN.2004080648)

Brosius FC III 2008 New insights into the mechanisms of fibrosis and sclerosis in diabetic nephropathy. Reviews in Endocrine and Metabolic Disorders 9 245-254. (doi:10.1007/s11154-008-9100-6)

Chen HS, Wu TE, Jap TS, Lu RA, Wang ML, Chen RL \& Lin HD 2007 Subclinical hypothyroidism is a risk factor for nephropathy and cardiovascular diseases in type 2 diabetic patients. Diabetic Medicine $\mathbf{2 4}$ 1336-1344. (doi:10.1111/j.1464-5491.2007.02270.x)

Chiarelli F, Gaspari S \& Marcovecchio ML 2009 Role of growth factors in diabetic kidney disease. Hormone and Metabolic Research 41 585-593. (doi:10. 1055/s-0029-1220752)

Cohen MP, Lautenslager GT \& Shearman CW 2001 Increased urinary type IV collagen marks the development of glomerular pathology in diabetic d/db mice. Metabolism: Clinical and Experimental 50 1435-1440. (doi:10.1053/meta.2001.28074)

Feliers D, Duraisamy S, Faulkner JL, Duch J, Lee AV, Abboud HE, Choudhury GG \& Kasinath BS 2001 Activation of renal signaling pathways in $\mathrm{db} / \mathrm{db}$ mice with type 2 diabetes. Kidney International 60 495-504. (doi:10.1046/j.1523-1755.2001.060002495.x)

den Hollander JG, Wulkan RW, Mantel MJ \& Berghout A 2005 Correlation between severity of thyroid dysfunction and renal function. Clinical Endocrinology 62 423-427. (doi:10.1111/j.1365-2265.2005.02236.x)

Iglesias P \& Diez JJ 2009 Thyroid dysfunction and kidney disease. European Journal of Endocrinology/European Federation of Endocrine Societies $\mathbf{1 6 0}$ 503-515. (doi:10.1530/EJE-08-0837)

Islam S, Yesmine S, Khan SA, Alam NH \& Islam S 2008 A comparative study of thyroid hormone levels in diabetic and non-diabetic patients. Southeast Asian Journal of Tropical Medicine and Public Health 39 913-916.

Kaplan MM \& Young JB 1987 Abnormal thyroid hormone deiodination in tissues of ob/ob and db/db obese mice. Endocrinology 120 886-893. (doi:10.1210/endo-120-3-886)

Koya D, Haneda M, Nakagawa H, Isshiki K, Sato H, Maeda S, Sugimoto T, Yasuda H, Kashiwagi A, Ways DK et al. 2000 Amelioration of accelerated diabetic mesangial expansion by treatment with a PKC beta inhibitor in diabetic $\mathrm{db} / \mathrm{db}$ mice, a rodent model for type 2 diabetes. FASEB Journal $\mathbf{1 4}$ 439-447.

Koya D, Hayashi K, Kitada M, Kashiwagi A, Kikkawa R \& Haneda M 2003 Effects of antioxidants in diabetes-induced oxidative stress in the glomeruli of diabetic rats. Journal of the American Society of Nephrology 14 S250-S253. (doi:10.1097/01.ASN.0000077412.07578.44)

Kumar D, Robertson S \& Burns KD 2004 Evidence of apoptosis in human diabetic kidney. Molecular and Cellular Biochemistry 259 67-70. (doi:10. 1023/B:MCBI.0000021346.03260.7e)

Lehmann R \& Schleicher ED 2000 Molecular mechanism of diabetic nephropathy. Clinica Chimica Acta 297 135-144. (doi:10.1016/S00098981(00)00240-0)

Lin Y \& Sun Z 2010a Current views on type 2 diabetes. Journal of Endocrinology 204 1-11. (doi:10.1677/JOE-09-0260)

Lin Y \& Sun Z $2010 b$ Thyroid hormone potentiates insulin signaling and attenuates hyperglycemia and insulin resistance in a mouse model of type 2 diabetes. British Journal of Pharmacology 162 597-610. (doi:10.1111/j.14765381.2010.01056.x)

Price PM 2007 Diabetes: caught in the Akt? Kidney International 71 839-841. (doi:10.1038/sj.ki.5002200)

Rane MJ, Song Y, Jin S, Barati MT, Wu R, Kausar H, Tan Y, Wang Y, Zhou G, Klein JB et al. 2010 Interplay between Akt and p38 MAPK pathways in the regulation of renal tubular cell apoptosis associated with diabetic nephropathy. American Journal of Physiology. Renal Physiology 298 F49-F61. (doi:10.1152/ ajprenal.00032.2009)

Ruggenenti P \& Remuzzi G 1998 Nephropathy of type-2 diabetes mellitus. Journal of the American Society of Nephrology 9 2157-2169.

Sharma K, McCue P \& Dunn SR 2003 Diabetic kidney disease in the $\mathrm{db} / \mathrm{db}$ mouse. American Journal of Physiology. Renal Physiology 284 F1138-F1144. (doi:10.1152/ajprenal.00315.2002)

Singer MA 2001 Of mice and men and elephants: metabolic rate sets glomerular filtration rate. American Journal of Kidney Diseases 37 164-178. (doi:10.1016/S0272-6386(01)80073-1)

Steffes MW, Osterby R, Chavers B \& Mauer SM 1989 Mesangial expansion as a central mechanism for loss of kidney function in diabetic patients. Diabetes 38 1077-1081. (doi:10.2337/diabetes.38.9.1077)

Suher M, Koc E, Ata N \& Ensari C 2005 Relation of thyroid disfunction, thyroid autoantibodies, and renal function. Renal Failure 27 739-742. (doi:10.1080/08860220500243338)

Suzuki D \& Miyata T 1999 Carbonyl stress in the pathogenesis of diabetic nephropathy. Internal Medicine 38 309-314. (doi:10.2169/internalmedicine. 38.309)

Tejada T, Catanuto P, Ijaz A, Santos JV, Xia X, Sanchez P, Sanabria N, Lenz O, Elliot SJ \& Fornoni A 2008 Failure to phosphorylate AKT in podocytes from mice with early diabetic nephropathy promotes cell death. Kidney International 73 1385-1393. (doi:10.1038/ki.2008.109)

van Welsem ME \& Lobatto S 2007 Treatment of severe hypothyroidism in a patient with progressive renal failure leads to significant improvement of renal function. Clinical Nephrology 67 391-393.

Zhu Y, Usui HK \& Sharma K 2007 Regulation of transforming growth factor beta in diabetic nephropathy: implications for treatment. Seminars in Nephrology 27 153-160. (doi:10.1016/j.semnephrol.2007.01.008)

Ziyadeh FN, Hoffman BB, Han DC, Iglesias-De La Cruz MC, Hong SW, Isono M, Chen S, McGowan TA \& Sharma K 2000 Long-term prevention of renal insufficiency, excess matrix gene expression, and glomerular mesangial matrix expansion by treatment with monoclonal antitransforming growth factor-beta antibody in $\mathrm{db} / \mathrm{db}$ diabetic mice. PNAS 97 8015-8020. (doi:10.1073/pnas.120055097)

Received in final form 30 January 2011

Accepted 9 February 2011

Made available online as an Accepted Preprint 9 February 2011 